\title{
The GlucoCoper-A Salutogenic Approach to Diabetes Distress
}

\author{
Sanjay Kalra, ${ }^{1}$ Manish Bathla, ${ }^{2}$ and Deepak Khandelwal ${ }^{3}$ \\ 1. Department of Endocrinology, Bharti Hospital, Karnal, India; 2. Department of Psychiatry, MM Institute of Medical Sciences and Research, Mullana, \\ India; 3. Department of Endocrinology, Maharaja Agrasen Hospital, New Delhi, India
}

DOI: https://doi.org/10.17925/USE.2018.14.1.30

$\mathrm{T}$ his communication describes the need for a salutogenic (health-promoting) attitude in our thoughts, communication, and action while managing diabetes. Such an approach is more patient-friendly than a pathogenesis or disease-based framework of medicine. Keeping this in mind, it could be more appropriate to measure positive aspects of life with diabetes, such as coping skills, rather than diabetes distress, which has a negative connotation. This article describes the utility of the GlucoCoper in screening, diagnosing, and managing diabetes distress.

\section{Keywords}

Adjustment disorder, anxiety, biopsychosocial, coping skills training,

depression, psychosocial, diabetes

Disclosure: Sanjay Kalra, Manish Bathla, and Deepak Khandelwal have nothing to disclose in relation to this article.

Review Process: This article is a short opinion piece and has not been submitted to external peer reviewers.

Authorship: All named authors meet the International Committee of Medical Journal Editors (ICMJE) criteria for authorship of this manuscript, take responsibility for the integrity of the work as a whole, and have given final approval to the version to be published.

open Access: This article is published under the Creative Commons Attribution Noncommercial License, which permits any noncommercial use, distribution, adaptation, and reproduction provided the original author(s) and source are given appropriate credit. (c) The Authors 2018

Received: May 8, 2018

Published Online: May 22, 2018

Citation: US Endocrinology, 2018;14(1):30-31

Corresponding Author: Sanjay Kalra,

Department of Endocrinology, Bharti Hospital,

Karnal, India. E: brideknl@gmail.com

Support: No funding was received in

the publication of this article.
Modern medicine bases its therapeutic interventions upon a thorough understanding of the pathogenesis of disease. This framework provides opportunity for the development of rational medical and surgical interventions, and promotes evidence-based management of illness. Such an approach, however, creates an ecosystem wherein the modern medical practitioner thinks, and communicates, keeping 'pathos' or disease as the center of all action. This contrasts with older, traditional schools of care, which tend to emphasize health, wholeness, and wellbeing as their aims and objectives. ${ }^{1,2}$ Such discrepancy may explain the dissatisfaction that the general public feels with our services.

Though delivered to the best of our ability, we are sometimes unable to explain the rationale of our interventions, thus creating lack of confidence and distrust. A 3l strategy (interaction, information, involvement) has been proposed to bridge the patient-provider gap in communication. ${ }^{3}$ This, however, may not meet expectations, as it is extremely challenging to convert 'medicalese' into layman language.

\section{Salutogenic thought}

A simpler means of improving health care satisfaction would be to adopt a salutogenic (health-promoting) thought and speech process while communicating with patients and the public. Mahatma Gandhi once defined harmony as a state when one's thoughts, words, and actions are concordant with each other. A similar situation should be created in the health care system, where health providers use pro-health language to convey their concern for the community's health. ${ }^{4}$ This is especially important in chronic care, as patients living with chronic disease experience relatively greater contact with healthcare providers.

\section{The stress of adjustment}

Chronic disease is characterized by a strong psychosocial component, in addition to biomedical dysfunction. As lifestyle is an important contributor to chronic disease pathophysiology, lifestyle modification becomes an integral strategy of management. This requires multiple and significant changes, which can create a lot of discomfort and distress. ${ }^{5}$ This in turn, may lead to impaired adjustment to the chronic disorder. In diseases such as diabetes and hypothyroidism, this has been termed as "diabetes distress" and "thyro-stress" $.6,7$

The onomastic construct of diabetes distress is a negative-sounding one, which promotes a feeling of misery or unhappiness. This is similar to the now obsolete way of referring to a "patient" as "suffering" from diabetes. The choice of words is important in health: this opinion is backed by evidence and experience. ${ }^{8,9}$ We therefore need to find a salutogenic way of referring to diabetes distress. 
One way of doing so would be to adopt nomenclature from the International Classification of Disease (ICD)-10,10 or the Diagnostic and Statistical Manual (DSM-5). ${ }^{11}$ In these taxonomic systems, the clinical term "adjustment disorder" is used to describe a state in which one finds it difficult to cope with a particular stress, which may include living with a disease. 10,11

\section{The stress of coping}

Another way of describing diabetes distress would be as a coping disorder. This utilizes a positive verb (coping) with a negative noun (disorder). While "coping" conveys a feeling of optimism and action, the use of "disorder" can be defended as being less negative than "disease". Validated tools to assess coping can be used in conjunction with, or as replacement for, instruments designed to evaluate distress. ${ }^{12,13}$ Use of such questionnaires to screen, diagnose, and monitor coping skills promotes the use of a salutogenic attitude, oriented towards coping (a positive, dynamic verb) rather than distress (a negative "static" noun). A similar advantage is seen with positively named instruments, such as wellbeing and treatment satisfaction questionnaires. ${ }^{14,15}$

\section{Target-stress or solution?}

Disease cannot be managed until it is screened for, diagnosed, and monitored. However, diagnosis and management can occur together in clinical medicine. The concept of therapeutic patient education suggests that patient interaction and education has a direct therapeutic effect as well. Another term for this diagno-therapeutic strategy is "diabetes therapy by the ear", delivered with "words of comfort". ${ }^{16}$ Another example of concomitant diagnosis and therapy is theranostics, as in nuclear medicine. This involves using the same agent for imaging and treatment of a lesion. Nano theranostics implies the use of nanoparticles for both diagnosis and treatment. ${ }^{17}$

\section{The GlucoCoper}

Using the same psychometric tool to diagnose and manage disease, e.g., diabetes distress, would then qualify as psychotheranostics. This is now possible with salutogenically named and designed tools such as the Glucocoper.

The Glucocoper is a validated 6-item tool which quantifies coping skills in persons with diabetes. ${ }^{13}$ This assessment can be used to identify suboptimal coping styles and plan interventions for coping skills enhancement. Thus, the instrument functions as a salutogenic, health-promoting, or action-oriented interventional tool. This is in contrast to other questionnaires, which are passive reinforcers of a problem statement. The GlucoCoper serves a dual purpose, of quantifying the problem, and suggesting the solution, at the same time. ${ }^{5}$

We therefore suggest the use of the Glucocoper in assessment and follow-up of diabetes distress. This instrument can be used in conjunction with, or independent of, conventional distress scales. We also support debate upon renaming of the clinical condition of diabetes distress as a diabetes adjustment disorder, or preferably, a coping disorder. $\square$
1. Lindström B. Eriksson M. Salutogenesis J Epidemiol Community Health. 2005; 59:440-2.

2. Kalra S, Baruah MP, Sahay R. Salutogenesis in type 2 diabetes care: A biopsychosocial perspective. Ind I of Endocrinol Metab. 2018;22:169

3. Kalra S, Unnikrishnan AG, Baruah MP. Interaction, information, involvement (The 3l strategy): Rebuilding trust in the medical profession. Ind I of Endocrinol Metab. 2017:21:268.

4. Ritholz MD, Beverly EA, Brooks KM, Abrahamson MJ, Weinger K. Barriers and facilitators to self-care communication during medical appointments in the United States for adults with type 2 diabetes. Chronic illness. 2014;10:303-13.

5. Kalra S, Verma K, Singh YB. Management of diabetes distress. Pak Med Assoc. 2017;67:1625-7.

6. Fisher L, Skaff MM, Mullan JT, et al. Clinical depression versus distress among patients with type 2 diabetes: not just a question of semantics Diabetes Care 2007: 30:542-8.

7. Kalra S, Verma K, Balhara YP. Thyro-stress. Indian J Endocrino Metab. 2017;21:632

8. Ruberton PM, Huynh HP, Miller TA, et al. The relationship between physician humility, physician-patient communication, and patien health. Patient Educ Couns. 2016;99:1138-45.

9. Jucks R, Bromme R. Choice of words in doctor-patient communication: An analysis of health-related Internet sites. Health Communication. 2007:21:267-77.

10. World Health Organization. The ICD-10 Classification of Mental and Behavioural Disorders: Clinical Descriptions and Diagnostic Guidelines. Geneva: World Health Organization, 1992.

11. American Psychiatric Association. Diagnostic and Statistical Manual of Mental Disorders (DSM-5®), Fifth Edition, 2013: Arlington, US.

12. Polonsky WH, Fisher L, Earles J, et al. Assessing psychosocial distress in diabetes: development of the diabetes distress scale Diabetes Care. 2005;28:626-31.

13. Kalra S, Balhara YPS, Verma K, Kalra B. The GlucoCoper - a Tool for the Assessment of Coping Mechanisms. Eur Endocrinol. 2018;14:52-55.

14. Bech P, Olsen LR, Kjoller M, Rasmussen NK. Measuring well-being rather than the absence of distress symptoms: a comparison of the SF-36 Mental Health subscale and the WHO-Five well-being scale. Int J Methods Psychiatr Res. 2003:12:85-91.

15. Bradley C. Diabetes treatment satisfaction questionnaire. Diabetes Care. 1999;22:530

16. Kalra S, Unnikrishnan AG, Baruah MP. Diabetes therapy by the ear Indian J Endocrinol Metab. 2013; 17:S596-8.

17. Muthu MS, Leong DT, Mei L, Feng SS. Nanotheranostics application and further development of nanomedicine strategies for advanced theranostics. Theranostics. 2014;4:660. 